\title{
Taste reactivity and consumption measures in the assessment of overshadowing: Modulation of aversive, but not ingestive, reactivity
}

\author{
TODD E. THIELE, STEPHEN W. KIEFER, and SCOTT A. BAILEY \\ Kansas State University, Manhattan, Kansas
}

\begin{abstract}
Three dependent measures-a taste reactivity test, a two-bottle preference test, and a one-bottle extinction test-were used to investigate the conditioning effects of pairing a taste/taste compound with LiCl-induced illness in rats. Avoidance of saccharin consumption in the one-bottle test was attenuated if saccharin and denatonium were paired during illness training (overshadowing). Also, saccharin was found to be more palatable if paired with denatonium during training as reflected by aversive (but not ingestive) taste reactivity measures. It is argued that overshadowing was reflected mainly by a modulation of aversive taste reactivity behavior with little influence on ingestive taste reactivity. The results are discussed in terms of current palatability issues, and it is suggested that applying taste reactivity tests to phenomena associated with taste avoidance learning (e.g., overshadowing or potentiation) may further our understanding of the mechanisms that guide such learning.
\end{abstract}

When an animal consumes a novel tasting stimulus and ingestion is followed by toxin-induced illness, that animal will be less likely to consume the food in the future (Garcia \& Koelling, 1966). Typically, such learning has been referred to as a conditioned taste aversion. Grill (1985) has argued that such results do not necessarily warrant the conclusion that a taste aversion has been learned, since consumption measures do not directly reveal whether illness produces a negative hedonic shift.

A techniquè has been developed by Grill and Norgren (1978) to examine directly the palatability of taste substances in rats. A small amount of a test solution is infused directly into the mouth over a brief time period, and the animal's orofacial and bodily responses are videotaped and then analyzed in detail. Rats produce stereotypical mouth, tongue, and body movements in response to the administration of particular taste solutions. Grill (1985; see also Grill \& Berridge, 1985) has divided the responses into ingestive and aversive categories. Ingestive responses aid consumption, in that they move the fluid to the rear of the mouth where the fluid can be swallowed. On the other hand, aversive responses expel or remove the fluid from the mouth. By quantifying ingestive

\footnotetext{
The first author is now at the Department of Psychology, University of Washington, Seattle, WA 98195. The authors thank Mary Miller for her help in this project. We also thank Atomergic Chemetals Corporation, 91 Carolyn Boulevard, Farmingdale, NY 11735-1527, for supplying the denatonium saccharide. Correspondence should be addressed to S. W. Kiefer, Department of Psychology, Bluemont Hall, Kansas State University, Manhattan, KS 66506-5302 (e-mail: swkiefer@ksuvm. ksu.edu).
}

and aversive responses, one can measure palatability directly.

It is often the case that consumption measures and taste reactivity measures yield similar results after aversion learning. For example, Berridge, Grill, and Norgren (Experiment 2, 1981) infused rats with glucose during taste reactivity procedures and then injected them with lithium chloride $(\mathrm{LiCl})$. They found that ingestive-reactivity responses to the taste stimulus decreased and aversivereactivity responses increased after illness training. When the same animals were given a two-bottle preference test, the trained subjects were less likely to choose glucose (and more likely to choose water) than were the untrained subjects.

However, avoidance behavior and changes in palatability do not always correspond. Pelchat, Grill, Rozin, and Jacobs (1983) gave rats sucrose paired with $\mathrm{LiCl}$ illness or electric shock, while other rats were allowed to consume lactose (rats are lactose intolerant). All rats demonstrated a significant avoidance response to the appropriate sugar solution (sucrose or lactose), but only rats given sucrose- $\mathrm{LiCl}$ training demonstrated decreased ingestive reactivity and increased aversive reactivity (relative to pretraining levels) to the training solution. Furthermore, Parker (1993) showed that when sucrose was paired with reinforcing drugs (cocaine, phencyclidine, or methamphetamine), learned avoidance of sucrose was not motivated by a palatability shift because aversive taste reactivity was unaffected.

The purpose of the present project was to compare further the relationship between consumption and taste reactivity responding after subjects received complex 
taste stimuli paired with $\mathrm{LiCl}$-induced illness. Specifically, we were interested in examining the interaction of various taste stimuli associated together in a compound during illness conditioning. When a weak taste is paired with a strong taste and this compound is then associated with illness, a typical finding is that the subject avoids the weak taste stimulus to a lesser degree than would have occurred if that taste had been conditioned alone (Batsell \& Best, 1993; Kucharski \& Spear, 1985). This phenomenon has been labeled overshadowing and has been demonstrated in a variety of conditioning situations in addition to taste-avoidance training (see, e.g., Kamin, 1969; Miles \& Jenkins, 1973; Revusky, 1971).

At present, overshadowing experiments have only utilized consumption measures. It is therefore unclear if overshadowing reflects a modulation of palatability (such that the negative hedonic shift is attenuated as a result of overshadowing) or is simply the result of reduced avoidance independent of changes in palatability. Using the taste reactivity procedure allows one to examine these issues. In the present experiment, the interaction of denatonium saccharide (hereinafter called denatonium), a bitter substance (see Davis, Grover, \& Erickson, 1987), and saccharin was examined after taste-illness training by utilizing three dependent measures: a taste reactivity test based on the technique of Grill and Norgren (1978), a two-bottle preference test, and a one-bottle extinction test.

\section{METHOD}

\section{Subjects}

Thirty-four naive male Holtzman-derived (Sasco, Inc.) rats, weighing between 250 and $350 \mathrm{~g}$ at the beginning of the experiment, were caged individually and given food ad lib in a room with a 12:12-h light:dark cycle (lights on at 7:00 a.m.).

\section{Surgery}

Before the experiment began, subjects were implanted with intraoral fistulae that were used in the taste reactivity portion of the experiment (see Grill \& Norgren, 1978, for details). Rats were allowed to recover with ad-lib access to food and water for 3 days after surgery. Each animal's fistula was flushed daily with water throughout the experiment in order to ensure its viability.

\section{Taste Reactivity Scoring}

Responses to distilled water and the test solutions were videotaped, and the resulting trials were analyzed frame-by-frame by manually advancing the videotape and simultaneously recording each response on a scoring sheet. Each scored trial was 60 -sec long and was scored without knowledge of the solution to eliminate bias (the same experimenter scored all data). The specific taste reactivity responses that were analyzed were characterized as either ingestive or aversive. Ingestive responses included mouth movements and tongue protrusions. Aversive responses included gape, head shake, forelimb flail, fluid expulsion, and passive drip. Detailed descriptions of each response can be found in Grill and Norgren (1978). For purposes of data analyses, total ingestive and total aversive responding were calculated for each rat.

\section{Apparatus and Solutions}

The taste reactivity chamber was a clear Plexiglas cylinder $22.2 \mathrm{~cm}$ in inside diameter and $25.4 \mathrm{~cm}$ in height. The chamber rested on a glass base that was mounted over a mirror so that the animal's ventral side could be videotaped during the infusion process. An infusion pump with a $10-\mathrm{ml}$ glass barrel syringe was used to infuse the solutions via PE tubing that connected the syringe with the intraoral fistula. Fluid was infused into the oral cavity at a rate of $1 \mathrm{ml} / \mathrm{min}$. Calibrated sipper tubes were mounted to the front of the rats' cages and were used to collect consumption measures. The amount of fluid consumed was recorded to the nearest $0.5 \mathrm{ml}$.

The solutions used were: $0.15 \%$ saccharin mixed by adding $1.5 \mathrm{~g}$ of saccharin to $1 \mathrm{~L}$ of distilled water; $0.005 \%$ denatonium mixed by adding $0.05 \mathrm{~g}$ of denatonium to $1 \mathrm{~L}$ of distilled water; and saccharindenatonium mixed by adding $1.5 \mathrm{~g}$ of saccharin and $0.05 \mathrm{~g}$ of denatonium to $1 \mathrm{~L}$ of distilled water. The illness agent used was $0.15 \mathrm{M} \mathrm{LiCl}$ intubated at a dose of $2 \%$ of body weight.

\section{Procedure}

After recovery from surgery, the animals were distributed to groups based on body weight: Group SAC $(n=8)$, Group MIXSAC $(n=7)$, Group DEN $(n=7)$, Group MIXDEN $(n=6)$, and Group CON $(n=6)$. Groups SAC and DEN were conditioned after consumption of a taste element (saccharin or denatonium, respectively) and Groups MIXSAC and MIXDEN were conditioned after consumption of the saccharin-denatonium compound. Because the focus of the study was to compare groups conditioned after consumption of a taste element with groups conditioned after consumption of a taste compound, and to economize costs, a complete set of unpaired control groups was not included. Instead, all subjects in Group CON were given untrained access to both saccharin and denatonium (order of taste presentation counterbalanced between subjects) during testing. The testing procedure was then divided into two phases: taste reactivity and consumption.

Taste reactivity. Over 3 days, the animals were placed in the taste reactivity chamber for $3 \mathrm{~min} /$ day to acclimate them to that environment. On the following 3 days, the animals were placed in the chamber for $1 \mathrm{~min} /$ day and infused with distilled water. All rats were infused with distilled water during the 7th day and behaviors were videorecorded on that day and all days thereafter during the taste reactivity phase. Following acclimation, rats were infused with their appropriate solution ( $1 \mathrm{ml}$ over $1 \mathrm{~min}$ ) and immediately intubated with $\mathrm{LiCl}$; Group SAC received the saccharin solution, Groups MIXSAC and MIXDEN received the saccharin-denatonium solution, and Group DEN received the denatonium solution. Half the subjects in Group coN were infused with saccharin, the other half with denatonium; these animals were not intubated with the toxin. On the following day, all groups except coN were given a baseline infusion of distilled water; the rats in Group coN that previously received saccharin were infused with denatonium, and those that received denatonium were infused with saccharin. On the final taste reactivity day, subjects were given the critical taste reactivity test: Groups SAC and MIXSAC were infused with saccharin and Groups DEN and MIXDEN were infused with denatonium.

Consumption. After the taste reactivity test, all rats were acclimated to a water deprivation schedule over a 4-day period. They were given 20 min of access to distilled water via sipper tubes at 10 a.m., at which time fluid consumption was measured. At 5:00 p.m., the animals were given $10 \mathrm{~min}$ of access to distilled water as supplemental fluid. This was followed by a two-bottle test day in which distilled water was placed in one bottle and the test solution was placed in the other (within each group, fluid positions were counterbalanced). Groups SAC and MIXSAC received saccharin as the test solution, while Groups DEN and MIXDEN received denatonium as the test solution. Half the animals in Group CON received saccharin as the test solution while the other half received denatonium as the test solution. On the following day, while conditioned animals received the one-bottle extinction test (see below), animals in Group CON that received saccharin were given denatonium as the test solution in a two-bottle test; those that received denatonium were given saccharin as the test solution.

On the final day of the study, the experimental groups were given a one-bottle extinction exposure to the appropriate test solution over a 6-h period: Groups SAC and MIXSAC received access to the saccharin solution and Groups DEN and MIXDEN received access to the denatonium solution. Consumption data were recorded every hour. Because Group con continued with the two-bottle test on this day, data from that group were not collected during the one-bottle test. 


\section{RESULTS}

All statistical analyses (including Newman-Keuls tests) were evaluated at $p=.05$.

\section{Taste Reactivity}

Training. An analysis of variance (ANOVA) was run to compare ingestive responding between all trained groups during the taste-aversion acquisition trial and was significant $[F(3,24)=5.98]$. A Newman-Keuls test revealed that Group DEN produced significantly fewer ingestive responses $(M=65.43)$ than did Groups SAC, MIXSAC, and MIXDEN $(M \mathrm{~s}=152.88,159.43$, and 169.5, respectively). Similarly, an ANOVA was run to compare aversive responding between all trained groups during the taste-aversion acquisition day and was significant $[F(3,24)=5.22]$. Group DEN produced significantly more aversive responses $(M=12.57)$ than Groups SAC, MIXSAC, and MIXDEN ( $M s=3.37,5.71$, and 3.67, respectively). Together, these results indicated that denatonium was less palatable than saccharin or a compound stimulus containing saccharin and denatonium.

Testing. Separate ANOVAs were run for subjects that received the saccharin solution and for subjects that received the denatonium solution during the critical test, and data from Group con were included in these analyses to provide a measure of untrained reactivity to the taste elements. Figure la shows ingestive responding produced by groups tested with saccharin during the critical taste reactivity test. Differences between groups were statistically significant $[F(2,18)=10.86]$. The post hoc tests indicated that although Groups SAC and MIXSAC were similar, they both produced significantly fewer ingestive responses than did Group coN, which suggested that saccharin became less palatable after aversion training. Figure $1 \mathrm{~b}$ shows ingestive responding produced by groups tested with denatonium during the critical test; statistical analysis failed to reveal statistically significant differences between these groups.

Aversive responding produced by groups tested with saccharin during the critical taste reactivity test is depicted in Figure 1c; the difference between groups was significant $[F(2,18)=10.97]$. Group con made significantly fewer aversive responses than did both Groups SAC and MIXSAC, suggesting that the trained groups, SAC and MIXSAC, found saccharin to be less palatable. More importantly, Group MIXSAC made significantly fewer aversive responses than did Group SAC. This suggested that the presence of denatonium during conditioning overshadowed saccharin aversions; saccharin was less palatable in Group SAC than in Group MIXSAC. Figure 1d shows aversive responding produced by groups tested with denatonium; there were no statistically significant differences between these groups on this measure.

\section{Consumption}

Separate ANOVAs were run for the groups that received the saccharin solution and those that received the denatonium solution during the consumption tests. Data from the two-bottle test were converted into a consumption ratio for analyses (test solution/test solution + distilled water). An ANOVA was run to compare the groups

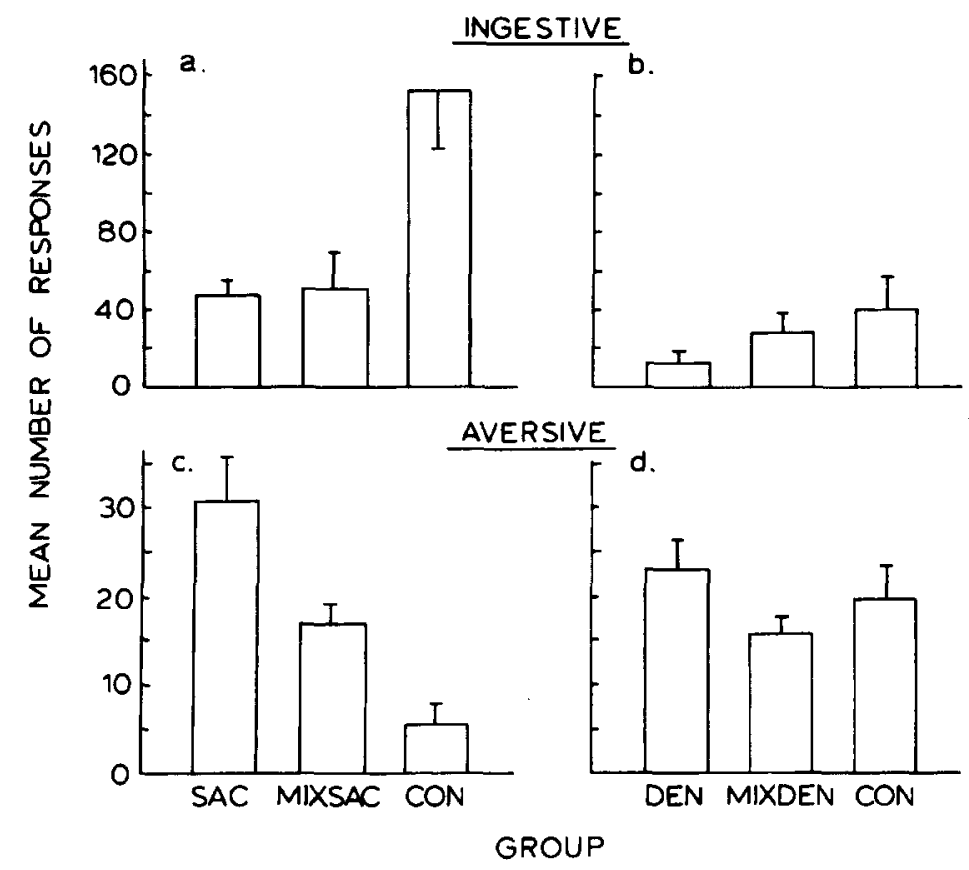

Figure 1. Mean $( \pm S E M)$ number of ingestive $(a-b)$ and aversive $(c-d)$ responses produced by each group during the taste reactivity test. The left column depicts groups tested with saccharin, and the right column depicts groups tested with denatonium. See text for explanation of group designations. 


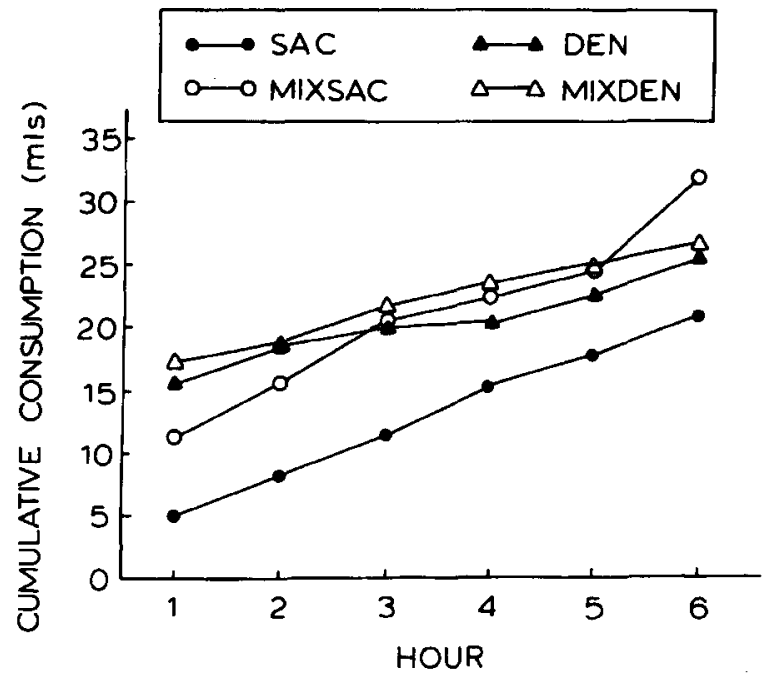

Figure 2. Mean cumulative consumption (in milliliters) during the one-bottle extinction test. Groups SAC and MIXSAC were tested with saccharin, and Groups DEN and MIXDEN were tested with denatonium.

that received the saccharin solution during the twobottle test, and the comparison was statistically significant $[F(2,18)=4.78]$. Although Groups SAC and MIXSAC generated similar preference ratios for saccharin $(M \mathrm{~s}=$ 0.15 and 0.04 , respectively), they both produced significantly smaller ratios than did Group coN $(M=0.47)$. This was evidence that Groups SAC and MIXSAC learned an avoidance to the saccharin solution. An ANOVA was run for the groups that received denatonium during the two-bottle test and was not statistically significant $(M \mathrm{~s}=$ $0.46,0.05$, and 0.47 for Groups DEN, MIXDEN, and CON, respectively). The inflated ratio for Group DEN (relative to Group MIXDEN) was caused by exclusive consumption of denatonium by 2 of the 7 animals in this group. Because these animals failed to sample any distilled water during this test (and because they had no previous training with a two-bottle procedure), they likely treated the two-bottle test as a one-bottle test.

Results from the one-bottle extinction test are presented in Figure 2. Data are presented as cumulative consumption measured every hour during the test; however, analyses examined only total fluid consumed. An ANOVA was run on the data from the groups that received saccharin and was significant $[F(1,13)=11.39]$. Overall, Group MIXSAC consumed more saccharin solution than did Group SAC. This suggested that the presence of denatonium during conditioning overshadowed saccharin avoidance. Analysis of consumption by groups that received denatonium during the one-bottle test failed to reveal significant effects.

Finally, ANOVAs were run to analyze the differences between all groups during the baseline taste reactivity days when water was infused and during baseline consumption days when water was presented in the drinking tubes. None of the effects reached statistical significance and verified that all groups were essentially equal with regard to baseline measures.

\section{DISCUSSION}

Group MIXSAC made significantly fewer aversive reactivity responses when infused with saccharin relative to Group SAC. Group MIXSAC also drank more saccharin solution than did Group SAC during the one-bottle extinction test. Both pieces of evidence suggested that denatonium overshadowed saccharin aversions. Furthermore, the data indicated that reduced avoidance to saccharin caused by overshadowing paralleled reduced aversive reactivity responding, suggesting that overshadowing behavior reflected a modulation of palatability. Contrary to what might be expected, modulation of palatability due to overshadowing was only apparent in aversive responses; there were no significant differences between Groups SAC and MIXSAC with regard to ingestive taste reactivity.

The overshadowing observed was not a symmetrical effect as saccharin did not overshadow denatonium avoidance. However, because Groups DEN and MIXDEN did not differ from Group CON in the taste reactivity tests (ingestive and aversive) or the two-bottle test, it appeared that little conditioning occurred to the denatonium taste stimulus. The authors are unable to explain the lack of conditioning with denatonium tested groups in the present experiment; however, strong conditioning to denatonium has been obtained in previous work (e.g., Batsell \& Best, 1993).

It should be noted that in other laboratories, it has been found that pairing denatonium with saccharin during illness training actually enhanced avoidance to saccharin relative to subjects trained with saccharin alone (Davis, Best, \& Grover, 1988; Davis, Bailey, Becker, \& Grover, 1990; Davis, Best, et al., 1990). This phenomenon is called potentiation. One clear procedural issue was that in past studies, rats were trained and tested in a drinking or consumption situation. In the present project, rats were given taste aversion training and initial testing in the taste reactivity chamber. It is possible that conditioning and testing in a taste reactivity situation promoted denatonium-overshadowed saccharin aversions instead of denatonium-potentiated saccharin aversions. Furthermore, the concentration of the denatonium used in the present study was substantially stronger than that employed by investigators who have found denatonium-potentiated saccharin aversions (Davis et al., 1988; Davis, Bailey, et al., 1990; Davis, Best, et al., 1990). The use of stronger denatonium concentrations may have promoted overshadowing instead of potentiation.

When subjects learned aversions to the taste stimuli, ingestivereactivity responses declined and aversive-reactivity responses increased relative to those of control groups. This result is in agreement with past research in which $\mathrm{LiCl}$ was used as the illness-producing agent (Berridge et al., 1981; Breslin, Grill, \& Spector, 1992). On the other hand, overshadowing of saccharin by denatonium was revealed only in aversive-reactivity responding. Breslin et al. (1992) have presented evidence that taste reactivity responses could be projected onto a single, unidimensional scale of palatability, with motivational states ranging from acceptance (ingestive) at one end to rejection (aversive) at the other. The fact that overshadowing was essentially restricted to aversive reactivity suggests that modulation of palatability occurred toward the rejection end of the scale; the overshadowed saccharin was still evaluated as aversive, but not as aversive as saccharin that was conditioned alone.

Many complex learning phenomena are associated with taste avoidance learning, including overshadowing. Past research investigating overshadowing (e.g., Batsell \& Best, 1993) has relied on consumption measures; avoidance of a taste stimulus is often attenuated if it is paired with a second taste during illness training. These data do not address the possible modulation of taste palatability caused by overshadowing. The present research indicated that overshadowing involved a modulation of aversive reactivity responses and had little influence on ingestive reactivity when saccharin and denatonium were used as taste stimuli. Clearly, one gains a more detailed picture of overshadowing when one uses taste reactivity tests. Relative to consumption measures, taste reactivity tests provide a greater characterization of the processes that 
guide the perception of taste stimuli after a complex aversion learning procedure (i.e., overshadowing). Applying taste reactivity tests to learning phenomena associated with taste avoidance learning (e.g., overshadowing and potentiation) may further our understanding of the mechanisms that guide such learning.

\section{REFERENCES}

BAtSELl, W. R., JR., \& Best, M. R. (1993). One bottle too many? Method of testing determines the detection of overshadowing and retention of taste aversions. Animal Learning \& Behavior, 21, 154-158.

BerRidge, K. C., GRILl, H. J., \& Norgren, R. (1981). Relation of consummatory responses and preabsorptive insulin release to palatability and learned taste aversions. Journal of Comparative \& Physiological Psychology, 95, 363-382.

Breslin, P. A., Grill, H. J., \& Spector, A. C. (1992). A quantitative comparison of taste reactivity behaviors to sucrose before and after lithium chloride pairings: A unidimensional account of palatability. Behavioral Neuroscience, 106, 820-836.

Davis, S. F., Bailey, S. A., Becker, A. H., \& Grover, C. A. (1990). Taste/taste potentiation as a function of age and stimulus intensity. Bulletin of the Psychonomic Society, 28, 201-203.

DAvis, S. F., Best, M. R., \& Grover, C. A. (1988). Toxicosis-mediated potentiation in a taste/taste compound: Evidence for within-compound associations. Learning \& Motivation, 19, 183-205.

Davis, S. F., Best, M. R., Grover, C. A., Bailey, S. A., Freeman, B. L., \& MAYLEBen, M. A. (1990). The effects of taste extinction on ingestional potentiation in weanling rats. Animal Learning \& Behavior, 18, 444-452.

Davis, S. F., Grover, C. A., \& Erickson, C. A. (1987). A comparison of the aversiveness of denatonium saccharide and quinine in humans. Bulletin of the Psychonomic Society, 25, 462-463.

GarCIA, I., \& KoElling, R. A. (1966). Relation of cue to consequence in avoidance learning. Psychonomic Science, 4, 123-124.

GRILL, H. J. (1985). Introduction: Physiological mechanisms in condi- tioned taste aversions. In N. S. Braveman \& P. Bronstein (Eds.), Experimental assessments and clinical applications of conditioned food aversions (Annals of the New York Academy of Sciences, Vol. 443, pp. 67-88). New York: New York Academy of Sciences. GrILl, H. J., \& BerRIDGE, K. C. (1985). Taste reactivity as a measure of the neural control of palatability. In J. M. Sprague \& A. N. Epstein (Eds.), Progress in psychobiology and physiological psychology (Vol. 11, pp. 2-61). New York: Academic Press.

GrILL, H. J., \& NoRgREN, R. (1978). The taste reactivity test: I. Mimetic responses to gustatory stimuli in neurologically normal rats. Brain Research, 143, 263-279.

Kamin, L. J. (1969). Predictability, surprise, attention, and conditioning. In B. A. Campbell \& R. M. Church (Eds.), Punishment and aversive behavior (pp. 279-296). New York: Appleton-CenturyCrofts.

KUCHARSKI, D., \& SPEAR, N. E. (1985). Potentiation and overshadowing in preweanling and adult rats. Journal of Experimental Psychology: Animal Behavior Processes, 11, 15-34.

Miles, C. G., \& Jenkins, H. M. (1973). Overshadowing in operant conditioning as a function of discriminability. Learning \& Motivation, 4, 11-27.

Parker, L. A. (1993). Taste reactivity responses elicited by cocaine-, phencyclidine-, and methamphetamine-paired sucrose solutions. Behavioral Neuroscience, 107, 118-129.

Pelchat, M. L., Grill, H. J., Rozin, P., \& Jacobs, J. (1983). Quality of acquired responses to tastes by Rattus norvegicus depends on type of associated discomfort. Journal of Comparative Psychology, 97, 140-153.

REVUSKY, S. (1971). The role of interference in association over a delay. In W. K. Honig \& P. H. R. James (Eds.), Animal memory (pp. 151-213). New York: Academic Press.

(Manuscript received May 24, 1995; revision accepted for publication September 18, 1995.) 